\title{
The Role of Hydroxyl Radicals in Iron Biogeochemical Cycling under Redox Dynamic Conditions
}

\author{
MAN TONG*, YANTING ZHANG, SONGHU YUAN
}

State Key Laboratory of Biogeology and Environmental Geology, China University of Geosciences, 388 Lumo Road, Wuhan 430074, P. R. China (tongman@cug.edu.cn)

Iron $(\mathrm{Fe})$ redox transformation in soils and sediments plays an essential role in the biogeochemical cycling of associated nutrients and elements. It is documented recently that hydroxyl radicals $(\cdot \mathrm{OH})$ can be produced upon oxygenation of $\mathrm{Fe}(\mathrm{II})$-bearing minerals in soils and sediments. As $\bullet \mathrm{OH}$ induces serious oxidative stress to microbes, it is likely that - $\mathrm{OH}$ produced upon $\mathrm{Fe}(\mathrm{II})$ oxygenation inactivates the coexisting dissimilatory iron-reducing bacteria and subsequently impacts Fe redox transformation. This hidden interplay between $\mathrm{Fe}$ species transformation and $\cdot \mathrm{OH}$ production in soils and sediments during anoxic-oxic cycles remains unexplored. In this study, a field sediment was incubated with Shewanella oneidensis strain MR-1 and treated for six anoxic-oxic cycles. Fe species transformation, - $\mathrm{OH}$ production and MR-1 activity variation were measured throughout the six cycles. Fe in the sediments prior to anoxicoxic cycles mainly existed in Fe-bearing silicates and $\mathrm{Fe}$ (hydr)oxides. For the anoxic periods, a portion of Fe(III) in sediments was either reduced to structural $\mathrm{Fe}(\mathrm{II})$ in (hydr)oxides and silicates or reductively dissolved to aqueous $\mathrm{Fe}^{2+}$. Total $\mathrm{Fe}(\mathrm{II})$ produced from $\mathrm{Fe}(\mathrm{III})$ bio-reduction increased in the first two anoxic periods but decreased in the following four anoxic periods. For the oxic periods, $\mathrm{Fe}$ (II) was oxidized along with a production of $\cdot \mathrm{OH}$, and the cumulative $\cdot \mathrm{OH}$ concentrations were around $31 \mu \mathrm{M}$ in the first three periods but decreased to $6.3 \mu \mathrm{M}$ in the subsequent three periods. MR-1 was inactivated by about 0.6 order of magnitude in the first two oxic periods, and the inactivation became insignificant for the later oxic periods. A strong interplay between $\mathrm{Fe}$ species transformation and $\cdot \mathrm{OH}$ production occurred in anoxic-oxic cycles. Fe(III) bioreduction by MR-1 in anoxic periods determined the content and speciation of $\mathrm{Fe}(\mathrm{II})$, which governed $\cdot \mathrm{OH}$ production in the subsequent oxic periods. The generated $\bullet \mathrm{OH}$ affected MR-1 activity in oxic periods, which further controlled $\mathrm{Fe}(\mathrm{III})$ bio-reduction in anoxic periods. The hidden interplay identified herein improves our understanding of the cycling of $\mathrm{Fe}$ and associated elements under redox fluctuating environments. 